\title{
DFT studies of cation binding by $\beta$-cyclodextrin
}

\author{
Anna Stachowicz $\cdot$ Anna Styrcz $\cdot$ Jacek Korchowiec $\cdot$ \\ Ali Modaressi $\cdot$ Marek Rogalski
}

Received: 4 February 2011/Accepted: 1 August 2011/Published online: 10 September 2011

(C) The Author(s) 2011. This article is published with open access at Springerlink.com

\begin{abstract}
Interactions of the $\beta$-cyclodextrin $(\beta$-CD) ligand with $\mathrm{Na}^{+}, \mathrm{Cu}^{+}, \mathrm{Mg}^{2+}, \mathrm{Zn}^{2+}$, and $\mathrm{Al}^{3+}$ cations were investigated using density functional theory modeling. The objective of this study was to give insight into the mechanism of cation complexation. Two groups of conformers were found. The first group preserved the initial orientation of glucopyranose residues inside the $\beta$-CD ligand. The mutual orientation of glucopyranose residues was strongly affected by the cation in the second group of conformers. The system interaction energy was decomposed into electrostatic (ES), Pauli and orbital contributions using the Ziegler-Rauk energy partitioning scheme. The total electrostatic energy, i.e., the sum of ES energy and polarization energy, is the dominating term in the interaction energy. In vacuum, the complexes formed with $\mathrm{Al}^{3+}$ were found to be more stable than with di- and monocations. The vacuum stability sequence was changed in aqueous solution.
\end{abstract}

Dedicated to Professor Akira Imamura on the occasion of his 77th birthday and published as part of the Imamura Festschrift Issue.

Electronic supplementary material The online version of this article (doi:10.1007/s00214-011-1014-9) contains supplementary material, which is available to authorized users.

A. Stachowicz · A. Styrcz · J. Korchowiec $(\bowtie)$

K. Guminski Department of Theoretical Chemistry,

Faculty of Chemistry, Jagiellonian University,

R. Ingardena 3, 30-060 Krakow, Poland

e-mail: korchow@chemia.uj.edu.pl

A. Modaressi - M. Rogalski

Laboratoire de Chimie et Applications,

IPEM, Université Paul Verlaine de Metz,

1 Boulevard Arago, 57070 Technopole, Metz, France
Keywords $\beta$-cyclodextrin · Guest-host complexes . Energy decomposition scheme $\cdot$ Natural orbitals for chemical valence $\cdot$ Cation binding

\section{Introduction}

Beta-cyclodextrin ( $\beta$-CD) is a cyclic oligomer of $\alpha$-D-glucose units. It contains seven glucopyranose residues (see scheme 1). The $\beta$-CD molecule is a shallow truncated cone with primary and secondary hydroxyl groups of smaller and bigger rims exposed to the solvent. The smaller ring is defined by primary hydroxyl oxygen atoms (O6 oxygens). The secondary hydroxyl groups (O2 and $\mathrm{O} 3$ oxygens) form the bigger rim. The molecule forms a hydrophobic cavity and is able to embed many organic molecules. Inclusion into the $\beta$-CD cavity can modify the physicochemical properties of the "guest" molecules (solubility, diffusion, sublimation, volatility, chromatographic mobility, hydrophobicity, reactivity, etc.) [1]. Taking into account bioadaptability of $\beta-\mathrm{CD}$, it is not surprising that $\beta-\mathrm{CD}$ has found widespread applications as encapsulating material for medicaments and food ingredients. Among other possible applications are those in the cosmetic, chemical, and biotechnological industries. Different aspects of cyclodextrin chemistry are addressed in recent reviews [1-5].

Even though $\beta$-CD attracts attention of many researchers, only a few ab initio investigations have been reported. High-level ab initio techniques are practically excluded due to the system's size. However, Hartree-Fock (HF) and density functional theory (DFT) based methods can be applied. Liu et al. [6] performed single point calculations at HF and DFT levels of theory on crystalline and PM3 optimized structures. The geometrical structure of $\beta$-CD was analyzed by Santos et al. [7] and Pinjari et al. [8] 


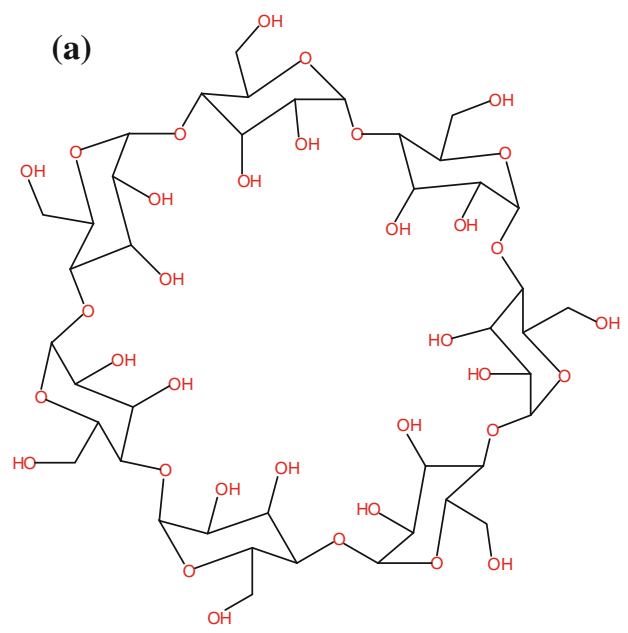

(b)

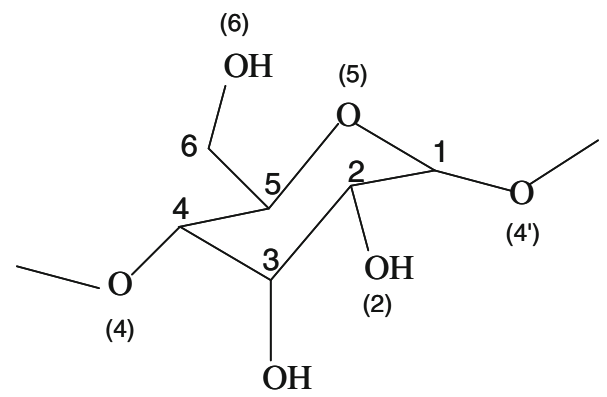

(3)

Scheme $1 \beta$-CD molecule (a) together with glucopyranose residues (b) and the assumed numbering of $\mathrm{C}$ and $\mathrm{O}$ atoms

Structure and dynamics of $\beta$-CD were investigated by Duarte et al. [9] at DFT tight binding level. A DFT study (B3LYP/6-31G**) of $\beta$-CD was reported by Wolschann et al. [10] Much more computational works can be found for the $\alpha$-cyclodextrin $(\alpha-C D)$ molecule which is composed of six glucopyranose residues. Low-energy conformers of $\alpha-\mathrm{CD}$ were investigated by Almeida et al. [11] at HF and DFT levels of theory with several basis sets ranging from split-valence double- $\zeta[6-31 \mathrm{G}(d, p)]$ to split-valence triple- $\zeta$ [6-311G $(2 d, 2 p)]$. Conformational analysis was also reported by Alderete and Jimenez [12] using PM3, HF/STO-3G, $\mathrm{HF} / 6-31 \mathrm{G}(d)$, B3LYP/6-31G $(d)$, and X3LYP/6-31G $(d)$ calculations. Geometries of $\alpha$-CD dimers for three possible orientations (head to head, tail to tail, and head to tail) were reported by Almeida et al. [13] at the BLYP/6-31G(d,p)//PM3 level.

It has been reported that metal cations can assist host/guest interactions [14]. Cai introduced $\mathrm{Fe}^{2+}$ and $\mathrm{Mg}^{2+}$ to enhance the detection of $\beta$-CD/toluene complexes [15]. Using electrospray mass spectroscopy, he proved the existence of ternary complexes (dication/ $\beta$-CD/toluene). Metal cation introduced to $\beta$-CD molecule can act as a catalytic center. Zhang and $\mathrm{Xu}$ showed that $\mathrm{M}^{2+} / \beta-\mathrm{CD}$ $(\mathrm{M}=\mathrm{Fe}, \mathrm{Co}, \mathrm{Cu}, \mathrm{Ni} \mathrm{Zn})$ catalyzes asymmetric aldol condensation [16]. In this paper, we have investigated (metal cation) $/ \beta-\mathrm{CD}$ complexes. Five cations were considered: $\mathrm{Mg}^{2+}, \mathrm{Zn}^{2+}, \mathrm{Cu}^{+}, \mathrm{Al}^{3+}$, and $\mathrm{Na}^{+}$. We have taken into account closed shell cations. For open shell cations, static correlation may be important and single-determinant approaches are not adequate. Unfortunately, the system size excludes multi-reference techniques. Our analysis was focused on stable conformers, binding energies, and their components obtained by applying the extended transition state (ETS) energy partitioning scheme [17]. The main charge reorganization channels were discussed using the natural orbital for chemical valence (NOCV) formalism [18]. Finally, conclusions and future prospects are discussed.

\section{Computational details}

All calculations were performed with the Gaussian 09 [19] suite of programs. Geometries for all investigated systems were optimized at density functional level of theory. We applied B3LYP hybrid functional [20] with 6-31G* basis set. The located minima of $\beta$-CD molecule were verified by Hessian eigenvalues. In $\mathrm{Mg}^{2+} / \beta-\mathrm{CD}$ and $\mathrm{Al}^{3+} / \beta-\mathrm{CD}$ systems several starting geometries with cations located on the smaller rim surface, as well as $1 \AA$ above and below this surface, were considered. The gradient optimization was employed. The existence of local minima was confirmed by Hessian eigenvalues. Every local minimum of $\mathrm{Mg}^{2+} / \beta-\mathrm{CD}$ was taken as starting configuration for the remaining cations. The complexes with lower rim oxygen atoms were considered. It has been suggested that cations in ternary complexes are located in the smaller rim and our aim is to build and characterize a model that can be used later on to study ternary systems and catalytic activity. In order to check for the existence of other conformers, a network controlled dynamic evolutionary algorithm was applied. The neural network dynamically tunes parameters of the evolutionary process. Each global optimization step was followed by a local gradient based optimization procedure. The MM2 force-field was applied. The optimization process was repeated ten times. More information about the algorithm is given elsewhere [21]. The lowest energy structures obtained at MM2 level of theory, those preserving chirality, were further optimized at B3LYP/6-31G* level of theory. The bond-order (BO) analysis was performed with the GAMESS package [22, 23]. The same 
functional and basis set were applied. Two types of BOs were considered. The first included covalent $\mathrm{BO}$ (CBO) data. [24, 25] In the second, covalent and ionic BO (CIBO) data [26, 27] were taken into account. The ETS-NOCV analysis [28] was done using ADF package [29] with basis set of triple- $\zeta$ (TZP) quality [30] at B3LYP level of theory using B3LYP/6-31G* geometry. Polarizable continuum model (PCM) with full geometry optimization was used with UFF radii and Van der Waals surface. The symmetry of $\beta$-CD molecule was not taken into account explicitly. The reported geometrical parameters were averaged over all symmetry related atoms (arithmetic mean over seven symmetry related values).

\section{Structure of $\beta$-CD in vacuum}

In Fig. 1, we have shown the most stable conformers of $\beta$-CD in vacuum. The plots were prepared with the use of visual molecular dynamics (VMD) package [31]. The system is highly symmetric. The primary hydroxyl groups form a ring of hydrogen bonds. Such spatial hydrogen bond arrangement, a kind of methanol heptamer (alcohol-toalcohol hydrogen bond orientation) makes the cavity practically closed from the smaller rim side. The results are consistent with those of Walschann et al. [10] obtained with a slightly larger basis set. The same situation was observed for $\alpha$-CD $[11,12]$. The hydrogen bonds are also formed in the bigger rim. Depending on the hydrogen donor and acceptor, left-hand $(-)$ and right-hand $(+)$ orientations can be distinguished. In the former orientation $(-)$, the intramolecular hydrogen bond is formed by $\mathrm{OH}$ group in position 2 and oxygen atom in position $3^{\prime}$ of the neighboring residue. In the later orientation $(+)$, the hydrogen bond is formed by $\mathrm{OH}$ in position 3 and $\mathrm{O}$ atom in position $2^{\prime}$. The left-hand $(-)$ and right-hand $(+)$ orientations correspond to counter-clockwise (cc) and clockwise (cw) orientations of Ref. [10]. Correspondingly, the orientation of the smaller rim hydrogen bonds consistent with the bigger rim is called left $(-$, counter-clockwise) or right-hand $(+$, clockwise). The orientation can be seen when looking from the smaller rim side. The existence of hydrogen bond belts from both sides of the cone is responsible for the rigidity of $\beta$-CD molecule and is probably responsible for the low water solubility of all cyclodextrins [1]. The other possible structures of $\beta$-CD result from internal rotation of the primary hydroxyl groups within the glucopyranose residues. In these structures, one can distinguish alcohol-to-ether hydrogen bonds as was reported in the case of $\alpha-\mathrm{CD}$ [11]. The secondary hydroxyl groups form a net of hydrogen bonds. Figure 2 shows two examples of these structures. The structure shown in panel (a) has alcohol-to-ether hydrogen bonds in the "smaller rim". The plots were prepared using VMD package [31]. This structure is open (o) to the environment from the smaller rim side and is called $\mathrm{o}(++)$ since both hydrogen belts have clockwise orientations. The second structure (panel b) has no hydrogen belt in the smaller rim. The hydrogen donor oxygen is at the shortest distance from the hydrogen atom of $\mathrm{H}-\mathrm{CHOH}$ moiety. The structure will be named $\mathrm{o}(--)$.The first and second signs in the bracket denote the smaller rim and the bigger rim orientations, respectively. The same convention was adopted for all conformers.

In Table 1 , the relative stabilities of $(-+),(--),(+-)$, and $(++)$ conformers are summarized. It is clear from this table that the orientation of the smaller rim hydrogen bond belt is responsible for the relative stability of conformers. The left-hand conformers are more stable than the righthand conformers. It is due to stronger hydrogen bonds in the smaller rim. The $\mathrm{O}-\mathrm{O}$ distance is of $0.02 \AA$ shorter for $(-)$ than for $(+)$ orientation. The bigger rim inter-residuum hydrogen bond is much longer. Even though the intra $\mathrm{O}-\mathrm{O}$ distance is short and comparable to that of the smaller rim, the hydrogen bond belt isn't formed since hydrogen atoms have unfavorable positions with respect to hydrogen donor
Fig. 1 A top view of the most stable conformers of $\beta$-CD molecule. $\mathbf{a}$ and $\mathbf{b}$ correspond to $(-+)$ and $(--)$ conformations, respectively
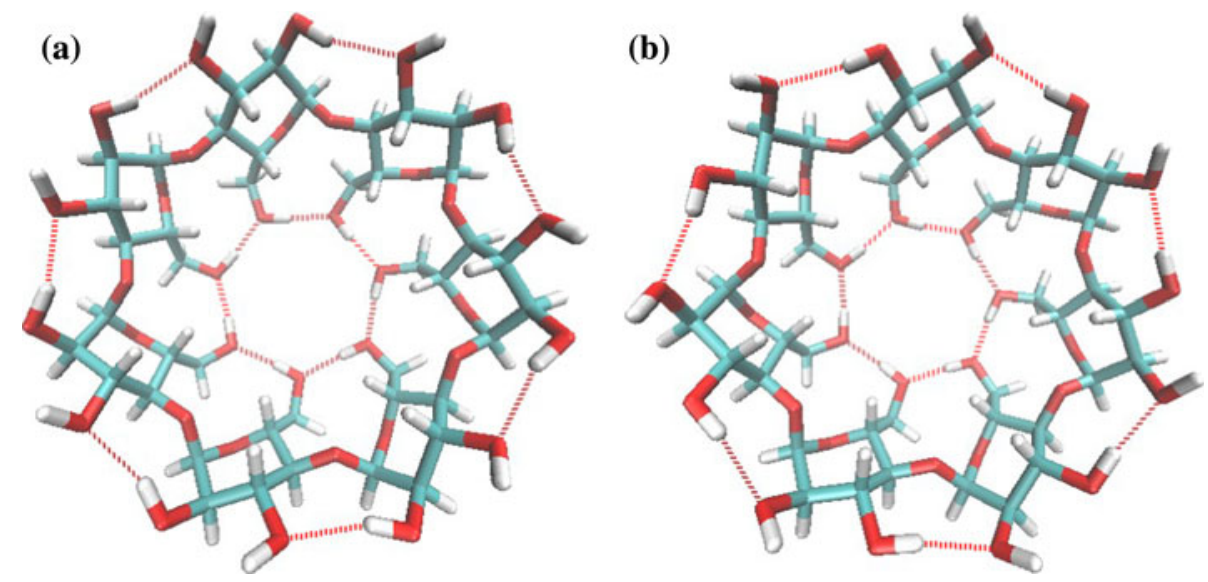
Fig. 2 The structures of $\beta$-CD opened from smaller rim side. The structure in a has clockwise orientation of hydrogen bond belts $(++)$. The second has no hydrogen belt in smaller rim
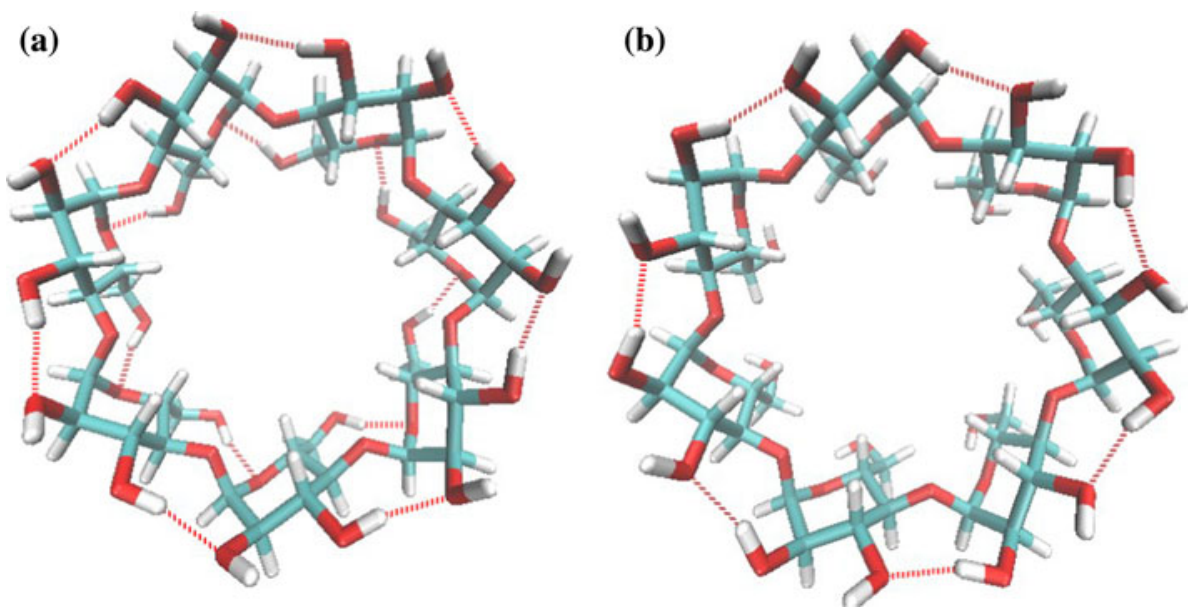

Table 1 Relative energies $(\mathrm{kcal} / \mathrm{mol})$ of located conformers of $\beta$-CD at B3LYP/6-31G* level of theory, together with distances between oxygen atoms involved in hydrogen bond formation $(\AA)$

\begin{tabular}{lrlll}
\hline Conformer & $\Delta E$ & $\begin{array}{l}R_{\mathrm{O}-\mathrm{O}} \\
(\text { smaller } \\
\text { rim) }\end{array}$ & $\begin{array}{l}R_{\mathrm{O}-\mathrm{O}} \text { (intra- } \\
\text { residuum) }\end{array}$ & $\begin{array}{l}R_{\mathrm{O}-\mathrm{O}} \text { (inter- } \\
\text { residuum) }\end{array}$ \\
\hline$(-+)$ & 0.0 & 2.81 & 3.08 & 2.87 \\
$(--)$ & 0.1 & 2.81 & 3.09 & 2.90 \\
$(+-)$ & 2.6 & 2.83 & 3.11 & 2.89 \\
$(++)$ & 2.8 & 2.83 & 3.10 & 2.86 \\
$\mathrm{o}(++)$ & 18.0 & $4.31(2.86)$ & 2.83 & 2.77 \\
$\mathrm{o}(--)$ & 20.2 & $4.44(2.84)$ & 2.86 & 2.82 \\
\hline
\end{tabular}

The numbers in parentheses are oxygen-oxygen separation (alcoholto-ether hydrogen bonds) for $\mathrm{O}(++)$ structure (see Fig. 2a) and oxygen-hydrogen separation for $\mathrm{o}(--)$ structure (see Fig. 2b)

oxygens which are forced by the ring geometry and all kind of distortion will strongly increase the steric strain. The $\mathrm{O}-\mathrm{O}$ distances obtained are very close to those obtained with a larger basis set and do not differ by more than $0.01 \AA$. Differences in relative energies are slightly more pronounced. The $(+-)$ and $(++)$ are about three times less stable than $(-+)$ and $(--)$ as was shown by our results. Single point calculations for slightly enlarged basis set (polarization function on $\mathrm{H}$ atoms bonded to oxygen atoms) performed on B3LYP/6-31G* geometries practically didn't change the relative energies. Therefore, the differences can be attributed to small change in the geometries obtained at B3LYP/6-31G**. The open-type structures, $\mathrm{o}(++)$ and $\mathrm{o}(--)$, are less stable in vacuum as compared to other structures. A relatively higher stability of the $\mathrm{o}(++)$ structure was observed. Both of these structures display much stronger hydrogen bonds in the bigger rim as compared to the closed-type structures. As was observed with closed-type structures, the open ones, $\mathrm{o}(+-)$ and $\mathrm{o}(-+)$ should be similar to $\mathrm{o}(++)$ and $\mathrm{o}(--)$ structures, respectively. The obtained hydrogen bond lengths are close to the experimental values of $2.850 \AA$ [32].

The geometrical parameters obtained at B3LYP/6-31G* level are summarized in Table 1 of supplementary materials. The reported data clearly indicates that for the open structures the values are closer to the experimental results [33]. The biggest discrepancies appear with primary hydroxyl oxygen atoms due to a practically free rotation of these groups. These groups may form hydrogen bonds with water molecules (crystal of $\beta$-CD contains about 9 waters per $1 \beta$-CD molecule).

\section{$4 \beta$-CD as a ligand}

As was stated by Norkus [34], most of the thousands of papers published each year on cyclodextrins concern cyclodextrin inclusion complexes and only a few deal with cyclodextrin metal complex chemistry. Metal ion complexes with cyclodextrins can be considered as models of metallo-enzymes. Such situation is not surprising because the presence of donor oxygen atoms in the smaller and bigger rims of $\beta$-CD should stimulate the complex formation. In order to give insight into this particular field of the cyclodextrin chemistry, we have considered the complexes of $\beta$-CD with $\mathrm{Na}^{+}, \mathrm{Mg}^{2+}, \mathrm{Al}^{3+}, \mathrm{Cu}^{+}$, and $\mathrm{Zn}^{2+}$. Taking into account that the distance between the opposite oxygen atoms is two times shorter within the smaller rim as compared with the bigger rim, we have considered coordination to the smaller rim. Undoubtedly, the mobility of the primary hydroxyl is also of great importance. It was also suggested that cation in ternary complexes is located in the smaller rim. The complexes formed by primary hydroxyl oxygen atoms belong to first group. We have also considered other types of coordination, mainly by secondary hydroxyl atoms (O2 and $\mathrm{O} 3)$. Formation of such complexes results from rotation of glucopyranose residues 
around linkage $\mathrm{C} 4-\mathrm{O} 4$ and $\mathrm{C} 1-\mathrm{O} 4{ }^{\prime}$ bonds. These complexes constitute the second group. Other types of complexes are less stable at MM2 level of theory than these of first and second groups.

The structures of located complexes are shown in Figs. 3 and 4. All plots were prepared using VMD package [31]. The calculated interaction energies are given in Table 3. The reported data are not corrected for basis set superposition error. We have presented the structure of $\mathrm{Mg}^{2+} / \beta-\mathrm{CD}$ complexes. The remaining systems $\left(\mathrm{Cu}^{+} / \beta-\mathrm{CD}, \mathrm{Na}^{+} / \beta-\mathrm{CD}\right.$, $\mathrm{Zn}^{2+} / \beta$-CD, and $\left.\mathrm{Al}^{3+} / \beta-\mathrm{CD}\right)$ are close in structure to the one of $\mathrm{Mg}^{2+} / \beta$-CD. Two groups of conformers are illustrated. Those from the first group (Fig. 3) preserves the bigger rim of $\beta$-CD. In other words, the initial orientation of glucopyranose residues in the $\beta$-CD ligand isn't changed. In the second group (Fig. 4), one or two glucopyranose residue is rotated around $\mathrm{C} 1-\mathrm{O} 44^{\prime}$ and $\mathrm{C} 4-\mathrm{O} 4$ bonds.

The first group of conformers includes four main structures, denoted as 1A-1D. In the complex, the high symmetry is lost. The cation is bonded to at least three primary hydroxyl oxygen atoms. In the structure, 1A three neighboring primary hydroxyls form coordination bonds with the cation. The coordination number of cation is equal to 3. This type of coordination wasn't observed for $\mathrm{Al}^{3+} / \beta$ $\mathrm{CD} ; \mathrm{Al}^{3+}$ tends to build into the wall of $\beta-\mathrm{CD}$ and coordination number equals 4 . In structure $1 \mathrm{~B}$, every second primary hydroxyl is involved in the bond formation. Namely, the primary hydroxyl groups of the first, the third and the fifth residues are involved in the complex. As a result of geometry distortion, three hydrogen bonds between primary hydroxyl groups are broken. Instead, three others are formed. New bonds are of alcohol-to-ether type. The geometrical structure of $\mathrm{Al}^{3+} / \beta$-CD complex is different since all primary oxygen atoms coordinated to $\mathrm{Al}^{3+}$ lose hydrogen atoms or protons which are shifted to neighboring hydroxyl groups or ring oxygen atoms (O6$\mathrm{H}-\mathrm{O}^{\prime}{ }^{\prime}$ or $\mathrm{O} 6-\mathrm{H}-\mathrm{O}^{\prime}$ hydrogen bonds). In water solvent, the protons should be trapped by water molecules. The proton can be shifted to other oxygen atom, including bigger rim secondary hydroxyl oxygen. We checked the stability of a few such systems. They are less stable by about $1.0-3.0 \mathrm{kcal} / \mathrm{mol}$ depending on the position. In other complexes, hydrogen atoms remain in their original positions. The coordination number is equal to 3 . In structure $1 \mathrm{C}$, the primary hydroxyl oxygens of the first, the second and the forth residues form coordination bonds with the cation. The coordination number is equal to 3 . $\mathrm{In}^{3} l^{3+} /$ $\beta$-CD complex, a partial deprotonation takes place. Two primary hydroxyls which are involved in the bond formation lose protons. In structure $1 \mathrm{D}$, the cation has a higher
Fig. 3 Four different geometrical structures of $\mathrm{Mg}^{2+}$ / $\beta$-CD complexes which preserve initial orientation of glucopyranose residues
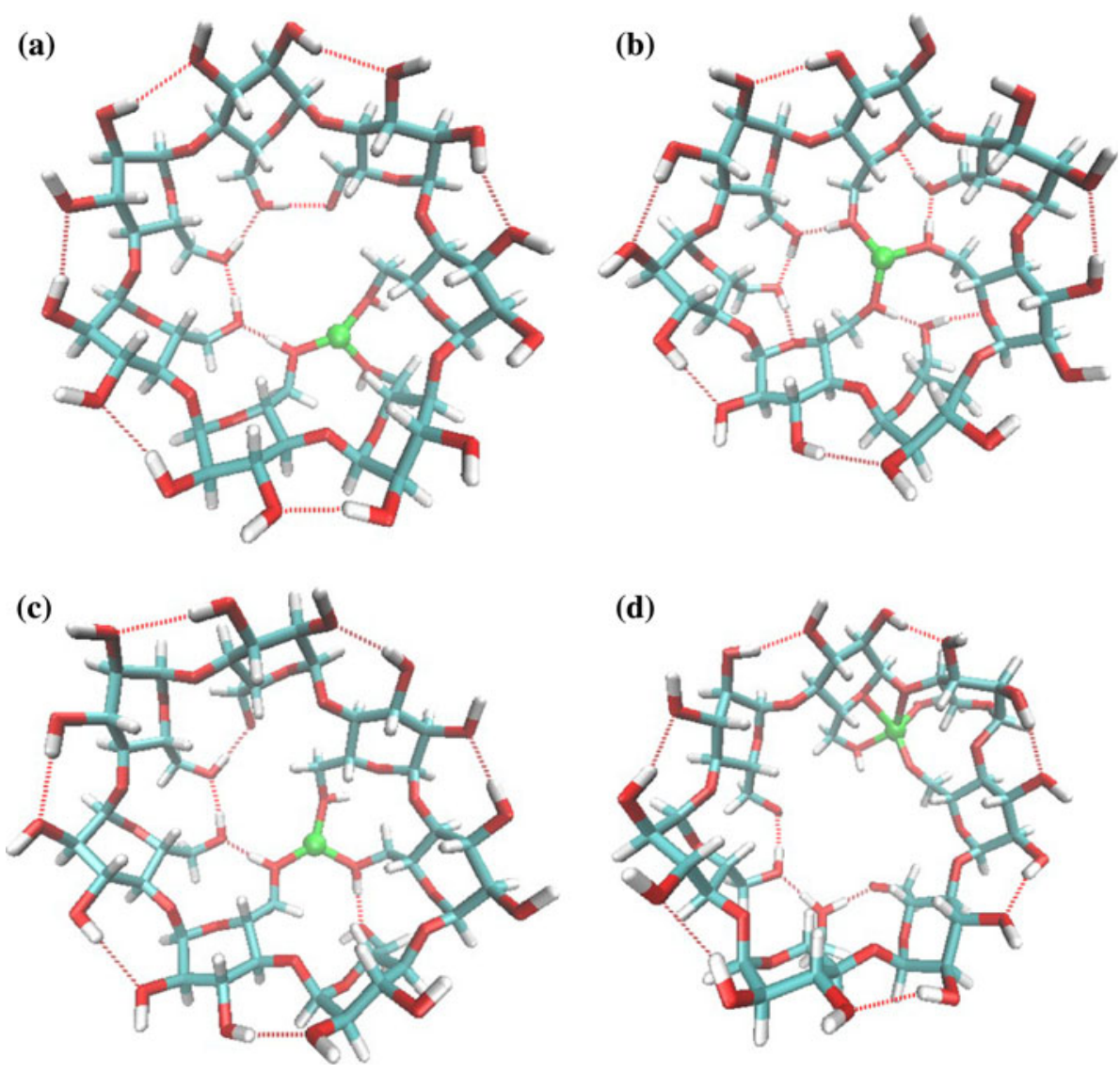
Fig. 4 Five different geometrical structures of $\mathrm{Mg}^{2+}$ / $\beta$-CD complexes where the mutual orientation of glucopyranose residues was strongly affected by cation
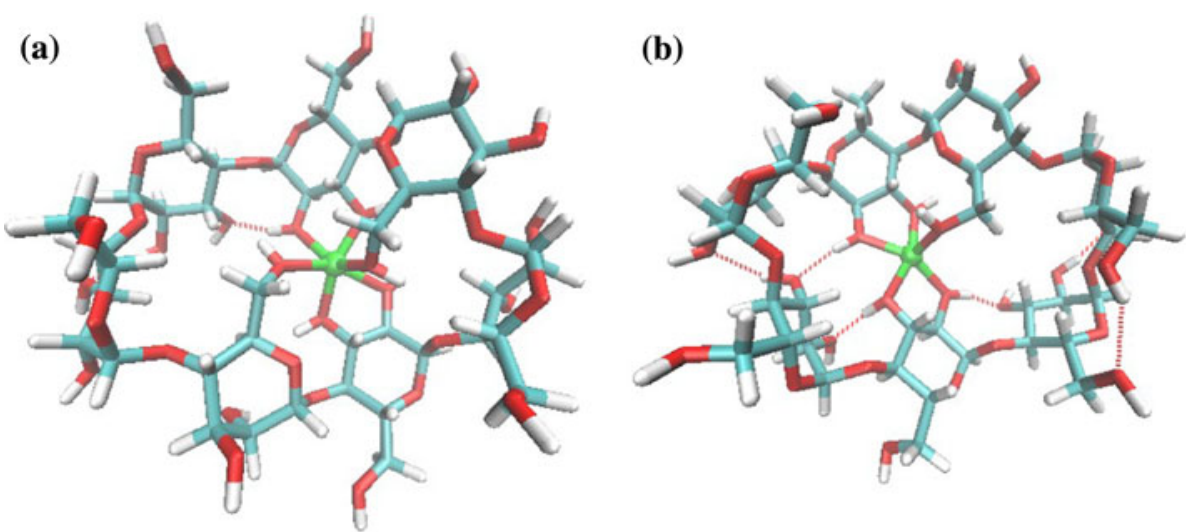

(c)

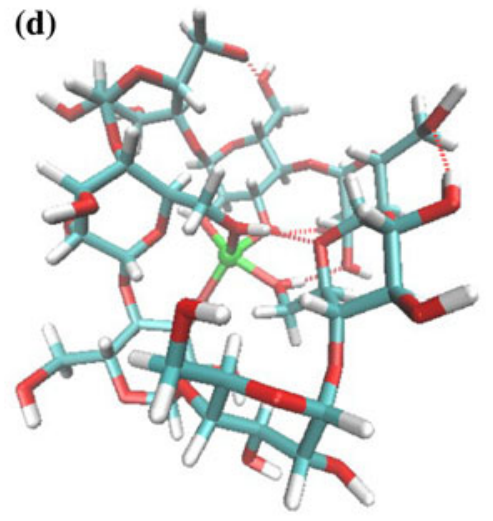

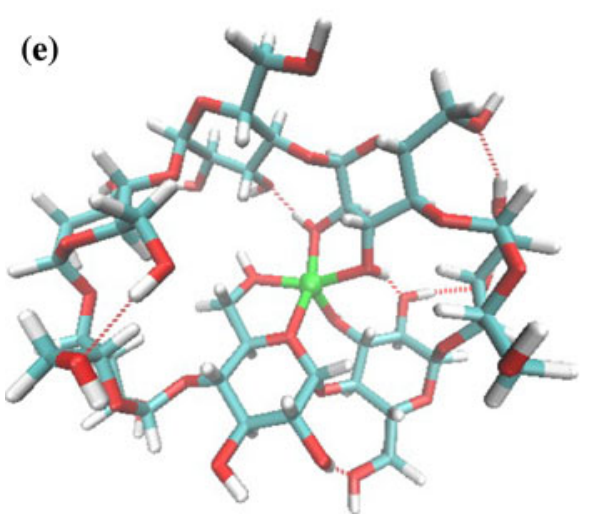

coordination number. Except for $\mathrm{Al}^{3+} / \beta-\mathrm{CD}$ complex it is equal to 5 . Three neighboring primary hydroxyls $(\mathrm{O}-6)$, linkage $\mathrm{O}-4$, and ring $\mathrm{O}-5$ oxygen atoms form coordination bonds. The coordination number of $\mathrm{Al}^{3+}$ is equal to 4 ; $\mathrm{O}-4$ oxygen doesn't participate in the bond formation. One of the primary hydroxyls that is involved in a coordination bond loses a proton. Such partial deprotonation takes place for each cation. One can expect that the structure 1D could be favored in dinuclear type complexes. The number of conformers can be doubled when taking into account the hydrogen bond belt in the bigger rim.

The second group of conformers is shown in Fig. 4. It includes five main structures, denoted as $2 \mathrm{~A}-2 \mathrm{E}$. The coordination numbers are equal to $6(2 \mathrm{~A})$ and $5(2 \mathrm{~B}-2 \mathrm{E})$, respectively. Structures $2 \mathrm{~A}-2 \mathrm{C}$ are similar to some degree. Namely, both secondary hydroxyl oxygen atoms (O2 and O3) of the opposite residues (residues 1 and 4) are involved in bond formation. The differences are connected with the remaining coordination bonds. In structure $2 \mathrm{~A}$, two primary oxygen atoms (O6) from third and fifth residues form coordination bonds. The primary oxygen atom from third/fifth residuum doesn't form bond with cation in structure $2 \mathrm{~B} / 2 \mathrm{C}$. Two primary hydroxyl oxygen atoms, two secondary $\mathrm{O} 2$ and one $\mathrm{O} 3$ form bonds with cation in structure 2D. In structure $2 \mathrm{E}$, O5 and $\mathrm{O} 6$ from first residue $\mathrm{O} 2$ from the second residue and both secondary hydroxyl oxygen atoms from forth residue are involved in bond formation. Deprotonation doesn't take 
place for structure from the second group. Interaction energies

$$
\begin{aligned}
& E_{\text {int }}=E_{\mathrm{X} / \beta-\mathrm{CD}}-E_{\mathrm{X}}-E_{\beta-\mathrm{CD}} \\
& \quad\left(\mathrm{X}=\mathrm{Na}^{+}, \mathrm{Mg}^{2+}, \mathrm{Al}^{3+}, \mathrm{Cu}^{+}, \mathrm{Zn}^{2+}\right),
\end{aligned}
$$

are collected in Table 2. The lowest energy structure of $\beta$-CD is taken, therefore, difference in the interaction energies for the same cation indicates the relative stability. For $\mathrm{Zn}^{2+} / \beta$-CD system, we have also checked the influence of polarization function on hydrogen atoms bonded to oxygen atoms on relative stabilities. The relative energies were changed by less than $0.8 \mathrm{kcal} / \mathrm{mol}$ when single point energies obtained at $\mathrm{B} 3 \mathrm{LYP} / 6-31 \mathrm{G}^{*}$ geometries were applied. Both groups of conformers are possible for dications. The structures of $\beta$-CD resulting from second group of conformers are less stable than these discussed in Sect. 2 by more than $60 \mathrm{kcal} / \mathrm{mol}$. This cost is compensated by additional coordination bonds. The differences between $E_{\text {int }}$ of the most stable conformers from both groups are less than $4 \mathrm{kcal} / \mathrm{mol}$. The differences are more pronounced for monocations and $\mathrm{Al}^{3+}$. Monocations prefer structure $1 \mathrm{C}$ while $\mathrm{Al}^{3+}$ prefers structure $1 \mathrm{~B}$. The most stable is the $\mathrm{Al}^{3+} / \beta$-CD system. Dicationic systems are next in the stability sequence; $\mathrm{Mg}^{2+} / \beta-\mathrm{CD}$ is less stable than $\mathrm{Zn}^{2+} / \beta$ CD. Monocationic systems are the least stable; $\mathrm{Na}^{+} / \beta-\mathrm{CD}$ is less stable than the $\mathrm{Cu}^{+} / \beta-\mathrm{CD}$ system.

The charges on the cations and their total valences are summarized in Table 3. The former are listed in the first line, whereas the latter are in the second line of each entries. Three population analyses were considered, namely Mulliken, Hirschfeld, and Voronoi population schemes. In addition, two types of valences are reported. The first valences are from CIBO scheme and they include covalent and ionic contributions [26, 27]. The second valences are from $\mathrm{CBO}$ scheme and they include covalent contributions only $[24,25]$. The Mulliken charges indicate a relatively big charge transfer (CT) from $\beta$-CD to the cation. Approximately, half of electron was transferred to the monocation. The amount of CT increases to one for dications and to two for $\mathrm{Al}^{3+}$. Quite different picture results from Hirschfeld charges; the amount of CT is small. The charges on $\mathrm{Na}$ and $\mathrm{Mg}$ atoms are close to 1 and 2, respectively. These results support common practice used in classical molecular dynamics simulation that these ions are treated as free species (without bonded interactions). The Voronoi charges are intermediate between Mulliken and Hirschfeld charges. The Hirshfeld charges are almost the same for all coordination modes. Except a few systems, the Voronoi charges are the same for both groups of complexes. Differences among both groups of complexes are more pronounced by Mulliken charges. The choice of population analysis is always problematic since atomic charges are not observables. The better idea is to choose population which is consistent with given observable quantities, see for example Refs. [35, 36].

The charge reorganization is also visible in $\mathrm{BO}$ data. The two BO data sets are different. The CBO valences are always smaller than the corresponding CIBO counterparts. This indicates a significant ionic contribution to the BOs. Despite this, the covalent contribution is bigger than ionic one. The strongest covalent bonding is observed for $\mathrm{Al}^{3+}$ / $\beta$-CD complex. It is reflected by the smallest difference in CIBO and CBO values. We would like to stress here that for covalently bonded atoms CBO and CIBO total valencies are almost identical.

\section{ETS-NOCV energy decomposition analysis}

In order to analyze different aspects of bonding, the interaction energy was decomposed into chemically meaningful contributions. Many decomposition schemes were proposed in the literature [17, 37-41]. We have chosen ETS scheme of Ziegler and Rauk [17]. Its recent development [28], the so-called ETS-NOCV scheme, links NOCV with the orbital energy. By merging energy partitioning and bond-order approaches, ETS-NOCV scheme provides a compact analysis of the chemical bond formation in terms of charge rearrangement channels and their corresponding energy contributions. Such detailed
Table 2 Interaction energies in $\mathrm{kcal} / \mathrm{mole}$ for structures $1 \mathrm{~A}-1 \mathrm{D}$ (see Fig. 3) and 2A-2E (see Fig. 4)

\begin{tabular}{llllll}
\hline & $\mathrm{Na}^{+} / \beta-\mathrm{CD}$ & $\mathrm{Mg}^{2+} / \beta-\mathrm{CD}$ & $\mathrm{Al}^{3+} / \beta-\mathrm{CD}$ & $\mathrm{Cu}^{+} / \beta-\mathrm{CD}$ & $\mathrm{Zn}^{2+} / \beta-\mathrm{CD}$ \\
\hline 1A & -67.1 & -269.5 & & -154.0 & -336.2 \\
1B & -65.9 & -279.0 & -776.2 & -144.7 & -331.3 \\
1C & -72.7 & -288.3 & -766.7 & -156.7 & -342.3 \\
1D & -65.6 & -290.8 & -769.4 & -116.3 & -345.4 \\
2A & -37.3 & -281.9 & -750.7 & -115.8 & -336.5 \\
2B & -35.8 & -283.7 & -762.9 & -113.3 & -329.9 \\
2C & -35.9 & -287.0 & -760.1 & -109.6 & -334.0 \\
2D & -23.8 & -283.5 & -754.6 & -101.1 & -328.7 \\
2E & -45.1 & -294.7 & -752.7 & -127.5 & -342.5 \\
\hline
\end{tabular}


Table 3 The Mulliken/ Hirschfeld/Voronoi charges on cations (first entry) and $\mathrm{CIBO} /$ CBO total valences (second entry)

\begin{tabular}{llllll}
\hline & $\mathrm{Na}^{+} / \beta-\mathrm{CD}$ & $\mathrm{Mg}^{2+} / \beta-\mathrm{CD}$ & $\mathrm{Al}^{3+} / \beta-\mathrm{CD}$ & $\mathrm{Cu}^{+} / \beta-\mathrm{CD}$ & $\mathrm{Zn}^{2+} / \beta-\mathrm{CD}$ \\
\hline $1 \mathrm{~A}$ & $0.54 / 0.97 / 0.77$ & $1.05 / 1.88 / 1.41$ & & $0.47 / 0.77 / 0.79$ & $0.91 / 1.60 / 1.30$ \\
& $1.59 / 0.89$ & $2.58 / 1.76$ & & $2.29 / 1.36$ & $2.45 / 1.98$ \\
1B & $0.49 / 0.96 / 0.77$ & $1.08 / 1.88 / 1.39$ & $1.08 / 2.76 / 1.73$ & $0.44 / 0.78 / 0.76$ & $1.06 / 1.61 / 1.31$ \\
& $1.69 / 1.00$ & $2.54 / 1.71$ & $3.66 / 3.21$ & $2.19 / 1.29$ & $2.29 / 1.74$ \\
1C & $0.52 / 0.97 / 0.76$ & $1.11 / 1.88 / 1.38$ & $1.16 / 2.76 / 1.74$ & $0.46 / 0.78 / 0.75$ & $1.06 / 1.62 / 1.31$ \\
& $1.65 / 0.93$ & $2.53 / 1.66$ & $3.42 / 3.07$ & $2.23 / 1.26$ & $2.30 / 1.73$ \\
1D & $0.45 / 0.96 / 0.75$ & $0.80 / 1.88 / 1.34$ & $1.11 / 2.76 / 1.81$ & $0.37 / 0.79 / 0.84$ & $0.88 / 1.63 / 1.33$ \\
& $1.96 / 1.06$ & $3.18 / 2.19$ & $3.58 / 3.19$ & $2.48 / 1.77$ & $2.57 / 2.12$ \\
2A & $0.34 / 0.96 / 0.74$ & $0.91 / 1.88 / 1.37$ & $1.24 / 2.76 / 1.84$ & $0.42 / 0.80 / 0.83$ & $1.05 / 1.64 / 1.34$ \\
& $2.19 / 1.26$ & $3.30 / 2.03$ & $3.67 / 3.02$ & $2.42 / 1.72$ & $2.58 / 1.99$ \\
2B & $0.44 / 0.97 / 0.74$ & $0.95 / 1.88 / 1.37$ & $1.19 / 2.76 / 1.80$ & $0.46 / 0.71 / 0.80$ & $1.10 / 1.64 / 1.35$ \\
& $2.02 / 1.09$ & $3.11 / 1.95$ & $3.69 / 3.10$ & $2.29 / 1.43$ & $2.47 / 1.90$ \\
2C & $0.36 / 0.96 / 0.74$ & $0.92 / 1.88 / 1.35$ & $1.25 / 2.76 / 1.81$ & $0.55 / 0.81 / 0.89$ & $1.09 / 1.64 / 1.35$ \\
& $2.15 / 1.24$ & $3.21 / 2.01$ & $3.68 / 3.03$ & $2.46 / 1.86$ & $2.54 / 1.95$ \\
2D & $0.39 / 0.96 / 0.74$ & $0.93 / 1.88 / 1.37$ & $1.26 / 2.76 / 1.83$ & $0.50 / 0.77 / 0.86$ & $1.09 / 1.65 / 1.36$ \\
& $2.16 / 1.17$ & $3.19 / 1.99$ & $3.62 / 3.01$ & $2.40 / 1.73$ & $2.51 / 1.93$ \\
2E & $0.43 / 0.96 / 0.74$ & $0.96 / 1.88 / 1.35$ & $1.23 / 2.76 / 1.35$ & $0.51 / 0.80 / 0.80$ & $1.09 / 1.64 / 1.34$ \\
& $2.14 / 1.11$ & $3.09 / 1.94$ & $3.56 / 3.01$ & $2.31 / 1.52$ & $2.46 / 1.91$ \\
\hline
\end{tabular}

description gives us information about charge penetration effects (polarization and charge transfer). These effects are usually disregarded in classical force-field calculation, where cations are considered as separate individuals. It means that interaction between cation and other atoms is modeled via electrostatic and Van der Waals contributions.

The ETS scheme decomposes $E_{\text {int }}$ into four contributions:

$E_{\text {int }}=E_{\mathrm{AB}}-E_{\mathrm{A}}^{0}-E_{\mathrm{B}}^{0}=E_{\mathrm{dist}}+E_{\mathrm{ES}}+E_{\mathrm{Pauli}}+E_{\mathrm{orb}}$,

where $E_{\mathrm{AB}}, E_{\mathrm{A}}^{0}$, and $E_{\mathrm{B}}^{0}$ are energies of supermolecule $\mathrm{AB}$ (complex), reactant $\mathrm{A}$ (acid, cation) and reactant $\mathrm{B}$ (base, ligand). The first component on the right-hand side of Eq. 2 describes geometry distortion $E_{\text {dist }}=E_{\mathrm{A}}+E_{\mathrm{B}}-E_{\mathrm{A}}^{0}-E_{\mathrm{B}}^{0}$. Geometries of reactants in the supermolecule are different from their minimum energy structure. The second component on the right-hand side of Eq. 2 is the electrostatic (ES) contribution. It represents the change in electrostatic interaction energy when the distorted fragments $\mathrm{A}$ and $\mathrm{B}$ are combined in the final supermolecule with the densities of noninteracting fragments kept frozen. $E_{\text {Pauli }}$ is the exchange-repulsion contribution. The last component in Eq. 2 is the orbital interaction contribution. It represents the interactions between the occupied molecular orbitals on $\mathrm{A}$ (B) with the unoccupied molecular orbitals of B (A) and the interactions between occupied and virtual orbitals within the same fragment A or B. The interfragment polarization corresponds to charge-transfer energy while the intrafragment polarization corresponds to polarization energy. This contribution includes other energy components that are well defined within perturbation approaches. This contribution can be further decomposed into NOCVs:

$E_{\mathrm{orb}}=\operatorname{tr}\left(\Delta \boldsymbol{D} \boldsymbol{F}^{\mathrm{TS}}\right)=\sum_{k=1}^{N / 2} v_{k}\left(F_{k k}^{\mathrm{TS}}-F_{-k-k}^{\mathrm{TS}}\right)=\sum_{k=1}^{N / 2} E_{k}^{\mathrm{orb}}$,

where $\boldsymbol{F}^{\mathrm{TS}}$ is the Kohn-Sham matrix computed for transition-state density $\rho^{\mathrm{TS}}=\left(\rho+\rho_{0}\right) / 2$ and $\boldsymbol{\Delta} \boldsymbol{D}=\boldsymbol{D}-\boldsymbol{D}_{0}$. Here, $\rho(\boldsymbol{D})$ and $\rho_{0}\left(\boldsymbol{D}_{0}\right)$ are densities (density matrices) of supermolecule and promolecule, respectively. The weighting factor $v_{k}$ is the eigenvalue of the equation: $\Delta \boldsymbol{D}$ $\boldsymbol{C}_{k}=v_{k} \boldsymbol{C}_{k}$. The NOCV eigenvectors appears in complementary pairs $\left(\varphi_{k}=\sum_{j} C_{k j} \phi_{j}, \varphi_{-k}=\sum_{j} C_{-k j} \phi_{j}\right)$ with the same absolute values of $v_{k}$ but opposite signs. In the NOCV representation, orb electron density can be decomposed into main charge reorganization channels:

$\Delta \rho_{\text {orb }}(\vec{r})=\sum_{k=1}^{N / 2} v_{k}\left(\left|\varphi_{k}(\vec{r})\right|^{2}+\left|\varphi_{-k}(\vec{r})\right|^{2}\right)=\sum_{k=1}^{N / 2} \Delta \rho_{k}(\vec{r})$.

The energy contributions are listed in Table 4. The negative or positive sign of a given contribution indicates a stabilizing or destabilizing effect. The energetic requirements for each energy component are obviously based on their definitions. Correspondingly, the $E_{\text {Pauli }}$ energy must be positive for closed shell subsystems, 
Table 4 ETS energy decomposition $(\mathrm{kcal} / \mathrm{mole})$ of $\mathrm{X} / \beta$-CD complex, where $\mathrm{X}=\mathrm{Na}^{+}, \mathrm{Mg}^{2+}, \mathrm{Al}^{3+}, \mathrm{Cu}^{+}$, and $\mathrm{Zn}^{2+}$

\begin{tabular}{|c|c|c|c|c|c|c|c|c|c|}
\hline Complex & $1 \mathrm{~A}$ & $1 \mathrm{~B}$ & $1 \mathrm{C}$ & $1 \mathrm{D}$ & $2 \mathrm{~A}$ & $2 \mathrm{~B}$ & $2 \mathrm{C}$ & $2 \mathrm{D}$ & $2 \mathrm{E}$ \\
\hline \multicolumn{10}{|l|}{$\mathrm{Na}^{+} / \beta-\mathrm{CD}$} \\
\hline ES & -67.7 & -69.2 & -75.5 & -72.0 & -88.2 & -91.3 & -89.6 & -96.7 & -91.3 \\
\hline Pauli & 20.1 & 17.8 & 21.0 & 18.4 & 19.3 & 18.2 & 16.0 & 18.3 & 24.2 \\
\hline orb & -30.7 & -33.3 & -32.0 & -35.8 & -37.9 & -34.6 & -36.7 & -38.7 & -38.1 \\
\hline \multicolumn{10}{|c|}{$\mathrm{Mg}^{2+} / \beta-\mathrm{CD}$} \\
\hline ES & -185.7 & -198.7 & -211.0 & -277.3 & -229.3 & -235.7 & -241.4 & -238.4 & -226.1 \\
\hline Pauli & 59.6 & 54.5 & 62.7 & 66.3 & 45.5 & 50.3 & 53.4 & 48.1 & 55.1 \\
\hline orb & -176.5 & -181.1 & -176.9 & -210.5 & -207.4 & -196.7 & -204.4 & -208.1 & -202.3 \\
\hline \multicolumn{10}{|c|}{$\mathrm{Al}^{3+} / \beta-\mathrm{CD}$} \\
\hline $\mathrm{ES}$ & - & -595.0 & -527.8 & -458.3 & -411.42 & -469.8 & -429.0 & -413.3 & -396.6 \\
\hline Pauli & & 136.0 & 139.1 & 123.2 & 84.02 & 100.8 & 99.4 & 93.2 & 95.0 \\
\hline orb & & -627.9 & -599.3 & -613.3 & -596.18 & -595.6 & -595.2 & -597.8 & -584.9 \\
\hline \multicolumn{10}{|l|}{$\mathrm{Cu}^{+} / \beta-\mathrm{CD}$} \\
\hline ES & -172.9 & -165.6 & -181.7 & -210.6 & -173.0 & -185.8 & -161.5 & -175.2 & -180.7 \\
\hline Pauli & 151.2 & 127.7 & 146.1 & 155.6 & 125.6 & 146.5 & 116.9 & 122.4 & 135.4 \\
\hline orb & -99.6 & -90.4 & -93.9 & -100.8 & -88.5 & -93.6 & -88.9 & -88.5 & -88.0 \\
\hline \multicolumn{10}{|c|}{$\mathrm{Zn}^{2+} / \beta-\mathrm{CD}$} \\
\hline ES & -343.1 & -261.0 & -280.0 & -332.3 & -278.4 & -280.3 & -287.5 & -282.9 & -272.8 \\
\hline Pauli & 147.8 & 116.5 & 132.3 & 124.1 & 109.3 & 98.7 & 102.5 & 97.6 & 105.3 \\
\hline orb & -251.6 & -233.4 & -231.1 & -253.6 & -248.5 & -237.1 & -244.4 & -248.4 & -242.6 \\
\hline
\end{tabular}

whereas the orb energy must be negative. The electrostatic energy can be either positive or negative. As can be expected, ES energy is negative for all complexes due to the interaction of oxygen lone electron pairs with cations. Each term of the energy partitioning is sensitive to the cation. The stabilizing contributions show a tendency consistent with that displayed by the interaction energies (Table 2): $E_{\mathrm{ES}}\left(\mathrm{Al}^{3+} / \beta-\mathrm{CD}\right)<E_{\mathrm{ES}}\left(\mathrm{Zn}^{2+} / \beta-\mathrm{CD}\right)<E_{\mathrm{ES}}$ $\left(\mathrm{Mg}^{2+} / \beta-\mathrm{CD}\right)<E_{\mathrm{ES}}\left(\mathrm{Cu}^{+} / \beta-\mathrm{CD}\right)<E_{\mathrm{ES}}\left(\mathrm{Na}^{+} / \beta-\mathrm{CD}\right)$ and $E_{\text {orb }}\left(\mathrm{Al}^{3+} / \beta-\mathrm{CD}\right)<E_{\text {orb }}\left(\mathrm{Zn}^{2+} / \beta-\mathrm{CD}\right)<E_{\text {orb }}\left(\mathrm{Mg}^{2+} / \beta-\mathrm{CD}\right)$ $<E_{\text {orb }}\left(\mathrm{Cu}^{+} / \beta-\mathrm{CD}\right)<E_{\text {orb }}\left(\mathrm{Na}^{+} / \beta-\mathrm{CD}\right)$. The Pauli energy exhibits a different behavior. With only a few exceptions, the Pauli energy is less destabilizing for main group elements than for transition metal cations: $E_{\mathrm{Pauli}}\left(\mathrm{Cu}^{+} /\right.$ $\beta$-CD $)>E_{\text {Pauli }}\left(\mathrm{Zn}^{2+} / \beta-\mathrm{CD}\right)>E_{\text {Pauli }}\left(\mathrm{Al}^{3+} / \beta-\mathrm{CD}\right)>E_{\text {Pauli }}$ $\left(\mathrm{Mg}^{2+} / \beta-\mathrm{CD}\right)>E_{\text {Pauli }}\left(\mathrm{Na}^{+} / \beta-\mathrm{CD}\right)$. Such behavior does not invert the order observed for the stabilizing contributions. There is no general rule concerning stabilization of a given conformer. Interaction energy is a result of a strong interplay between different energy components including deformation energy. For $\mathrm{Zn}^{2+} / \beta$-CD system, the conformer $1 \mathrm{D}$ is preferred while ES, Pauli and orb energies favor $1 \mathrm{~A}$, $2 \mathrm{D}$, and $1 \mathrm{D}$ conformers, respectively.

Except for $\mathrm{Al}^{3+} / \beta-\mathrm{CD}$, the absolute value of $E_{\mathrm{ES}}$ is the biggest. Thus, the electrostatic energy is the main source of stabilization. For $\mathrm{Al}^{3+} / \beta$-CD system, the orb energy is the main source of stabilization. It is connected with distance between cation and oxygen atoms: $r_{\mathrm{X}-\mathrm{O}}$. In the first group (structure $1 \mathrm{~A}-1 \mathrm{D}$ ), the bond length in $\mathrm{Al}^{3+} / \beta-\mathrm{CD}$ complex ranges from 1.66 to $1.79 \AA$ and is the shortest as compared to other systems. In $\mathrm{Zn}^{2+} / \beta$-CD complex, $r_{\mathrm{Zn}^{2+}-\mathrm{O}}$ ranges from 1.86 to $1.94 \AA$. In the case of $\mathrm{Cu}^{+} / \beta-\mathrm{CD}$ complex, $r_{\mathrm{Cu}^{+}-\mathrm{O}}$ ranges from 1.87 to $2.07 \AA$. For $\mathrm{Mg}^{2+} / \beta-\mathrm{CD}$ $r_{\mathrm{Mg}^{2+}-\mathrm{O}}$ changes from 1.92 to $1.98 \AA$. Bonds between cation and oxygen atoms are the longest for $\mathrm{Na}^{+} / \beta-\mathrm{CD}$ and ranges from 2.23 to $2.31 \AA$. Short bonds observed in $\mathrm{Zn}^{2+}$ / $\beta$-CD and $\mathrm{Cu}^{+} / \beta$-CD complexes are responsible for the increase in $E_{\text {Pauli. }}$. For $\mathrm{Cu}^{+} / \beta$-CD complexes, $E_{\text {Pauli }}$ is the second largest contribution to the interaction energy. The similar observation is valid for second group of conformers. However, all $r_{\mathrm{X}-\mathrm{O}}$ bonds are longer as compared to first group. The $r_{\mathrm{Al}^{3+}-\mathrm{O}}$ bond length ranges from 1.86 to $2.09 \AA$ A. In $\mathrm{Zn}^{2+} / \beta$-CD complex, $r_{\mathrm{Zn}^{2+}-\mathrm{O}}$ ranges from 2.00 to $2.44 \AA$. In the case of $\mathrm{Cu}^{+} / \beta$-CD complex, $r_{\mathrm{Cu}^{+}-\mathrm{O}}$ ranges from 1.90 to $2.53 \AA$. For $\mathrm{Mg}^{2+} / \beta-\mathrm{CD}, r_{\mathrm{Mg}^{2+}-\mathrm{O}}$ changes from 2.02 to $2.25 \AA$. Again the longest are bonds for $\mathrm{Na}^{+} /$ $\beta$-CD complex and range from 2.27 to $2.94 \AA$.

The data listed in Table 5 are obtained by separating orb energy into main charge reorganization channels. All reported numbers are negative. Such behavior is obvious since this energy contribution includes polarization and charge-transfer energies stabilizing the system. The corresponding charge reorganization plots are shown in Fig. 5. In order to limit the number of $\Delta \rho_{k}(\vec{r})$ isosurfaces (Eq. 4), 
Table 5 ETS/NOCV decomposition of $E_{\text {orb }}($ in $\mathrm{kcal} / \mathrm{mol})$ for $\mathrm{X} / \beta$-CD complexes $\left(\mathrm{X}=\mathrm{Na}^{+}, \mathrm{Mg}^{2+}, \mathrm{Al}^{3+}, \mathrm{Cu}^{+}\right.$, and $\left.\mathrm{Zn}^{2+}\right)$

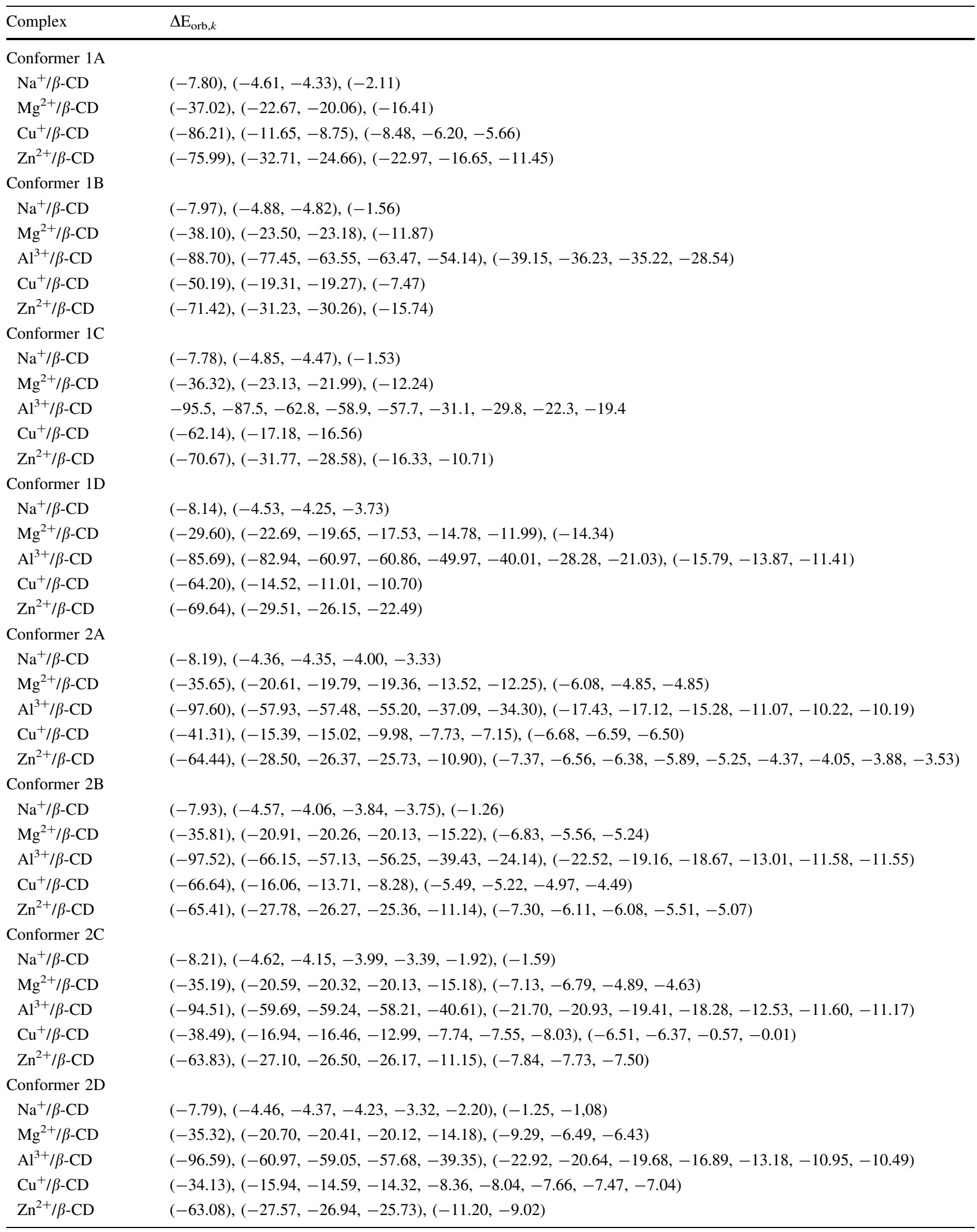


Table 5 continued

\begin{tabular}{ll}
\hline Complex & $\Delta \mathrm{E}_{\text {orb }, k}$ \\
\hline $\begin{array}{l}\text { Conformer 2E } \\
\mathrm{Na}^{+} / \beta \text {-CD }\end{array}$ & $(-7.80),(-4.34,-4.19,-4.10,-4.06),(-1.17,-1.03,-0.93,-0.91)$ \\
$\mathrm{Mg}^{2+} / \beta$-CD & $(-35.77),(-21.43,-20.62,-18.95,-15.43),(-7.16,-5.64,-5.36)$ \\
$\mathrm{Al}^{3+} / \beta-\mathrm{CD}$ & $(-98.50),(-61.00,-58.76,-56.61,-40.74),(-20.76,-20.02,-18.21,-17.84,-13.04,-12.94,-11.05,-10.36)$ \\
$\mathrm{Cu}^{+} / \beta-\mathrm{CD}$ & $(-39.09),(-16.26,-16.20,-10.44,-9.12),(-7.24,-7.04,-7.03)$ \\
$\mathrm{Zn}^{2+} / \beta-\mathrm{CD}$ & $(-65.91),(-28.52,-27.84,-23.44,-11.49),(-7.27,-6.45,-5.95)$ \\
\hline
\end{tabular}

Each number corresponds to the $k$-th contribution to $E_{\text {orb }}$ in the order of decreasing energy. First, second and third parentheses in each entry group CT, coordination and polarization channels, respectively. Only the most significant contributions have been listed

we have classified them as follows: $\sigma$ charge-transfer channel, $\sigma$-coordination channels and $\sigma, \pi$-polarization channels inside $\beta$-CD ligand. The data listed in Table 5 are grouped into these three categories. First, second and third parentheses in each entry correspond to $\mathrm{CT}$, coordination and polarization channels, respectively. Figure 5 illustrates examples of such channels. In structures $1 \mathrm{~A}, 1 \mathrm{~B}$, and $1 \mathrm{C}$, the central cation and the nearest oxygen atoms are almost coplanar. The angle between the surface defined by the oxygen atoms and plane defined by any other of three atoms is no larger than $3^{\circ}$. Assuming ideal $\mathrm{C}_{3}$ symmetry in the nearest environment of the cation, the symmetry adapted linear combination (SALC) of oxygen lone pairs $\left(\sigma_{1}, \sigma_{2}, \sigma_{3}\right)$ can be obtained. The lower indices denote the oxygen atoms. One of SALC, namely, $\varphi^{A}=\left(\sigma_{1}+\sigma_{2}+\right.$ $\left.\left.\sigma_{3}\right) / \sqrt{3}\right)$ belongs to irreducible representation $A$. The other two, $\left.\varphi_{1}^{E}=\left(2 \sigma_{1}-\sigma_{2}-\sigma_{3}\right) / \sqrt{6}\right)$ and $\left.\varphi_{2}^{E}\left(\sigma_{2}-\sigma_{3}\right) / \sqrt{2}\right)$, belong to irreducible representation $E$. Of course, rotation between $\varphi_{1}^{E}$ and $\varphi_{2}^{E}$ is allowed and gives other $E$-type SALCs. Central cation $3 s$ or $4 s$ orbitals belong to irreducible representation $A$ and they overlap with $\varphi^{A}$. As a result, one bonding and one anti-bonding molecular orbitals are obtained. The bonding molecular orbital is the main component of charge-transfer channel The $3 p_{x}\left(4 p_{x}\right)$ and $3 p_{y}\left(4 p_{y}\right)$ orbitals belong to irreducible representation $E$ and they overlap with $\varphi_{1}^{E}$ and $\varphi_{2}^{E}$. Taking into account the energy gap between $s$ and $p$ atomic orbitals, linear combination with the latter is less effective and molecular orbital is dominated by SALCs of the ligand oxygen atoms. These orbitals, belonging to irreducible representation $E$, define the coordination channels. Similar analysis can be performed for other types of local symmetries, e.g., C3v and $\mathrm{C} 4 \mathrm{v}$ observed in the second group of conformers. One should remember that the plots shown in Fig. 5 are density plots composed of two complementary densities $\left(\left|\varphi_{k}\right|^{2}\right.$ and $\left.\left|\varphi_{-k}\right|^{2}\right)$. Nevertheless, the charge-transfer and coordination channels can be recognized for all coordination types and cations. In the case of $\mathrm{Na}^{+} / \beta-\mathrm{CD}, \mathrm{CT}$ channel can be considered as coordination channel since contribution of $3 s_{\mathrm{Na}}$ is very small. For $\mathrm{Mg}^{2+} / \beta-\mathrm{CD}$, the contribution of $3 s_{\mathrm{Mg}}$ is bigger, however, not as big as for the remaining cations. This is illustrated in Fig. 5, panels a and b, with CT channels corresponding to $\mathrm{Zn}^{2+} / \beta-\mathrm{CD}$ and $\mathrm{Mg}^{2+} / \beta-\mathrm{CD}$ complexes. The $\mathrm{CT}$ channels are the most stabilizing contributions. In the case of transition metal cations, this channel is at least two or three times more stabilizing than the next one in the energy hierarchy. Figure 5, panels $\mathrm{c}$ and $d$, shows the coordination channels of the $\mathrm{Na}^{+} / \beta-\mathrm{CD}$ complex. Examples of polarization channels are shown in panels e and f, respectively. They are dominated by $2 p$ orbitals of oxygen atoms and are prepared to take part in back-donation from cation to ligand.

Even though, $E_{\mathrm{CT}}^{\mathrm{orb}}$ is the biggest stabilizing contribution, the remaining channels are also an important source of stabilization. They can be considered as polarization channels. The polarization energy (second-order electrostatic energy) is the next most important stabilizing contribution in $\mathrm{X} / \beta$-CD complexes. The most important is the first-order electrostatic contribution. It is in agreement with results obtained using different energy partitioning schemes for crown ether complexes [42].

\section{Solvent effects}

The interaction energies indicate that binding of $\mathrm{Al}^{3+}$ in $\beta$-CD is stronger than binding of other cations considered in this study. The stability is not an intrinsic property of cations. In other words, the original stability sequence, $\mathrm{Al}^{3+} / \beta-\mathrm{CD}>\mathrm{Zn}^{2+} / \beta-\mathrm{CD}>\mathrm{Mg}^{2+} / \beta-\mathrm{CD}>\mathrm{Cu}^{+} / \beta-\mathrm{CD}>$ $\mathrm{Na}^{+} / \beta-\mathrm{CD}$, can be changed by solvent. It has been demonstrated that explicit solvent molecules in the first solvent shell [43-46] are of crucial importance for describing geometries, energies and spectroscopic properties of solute. The effect beyond the first solvation shell was also investigated [44, 45]. The PCM approach can yield relative stabilization energies comparable to the predictions based 
Fig. 5 The main NOCV channels in $\mathrm{X} / \beta$-CD systems. $\mathbf{a}$ and $\mathbf{b}$ correspond to chargetransfer channels in $\mathrm{Zn}^{2+} / \beta$-CD and $\mathrm{Mg}^{2+} / \beta-\mathrm{CD}$, respectively. $\mathbf{c}$ and $\mathbf{d}$ are the coordination channels for $\mathrm{Na}^{+} / \beta$-CD. e and f illustrate polarization channels. The value of isosurface is equal to 0.003 for a-d and 0.001 for $\mathbf{e}$ and $\mathbf{f}$

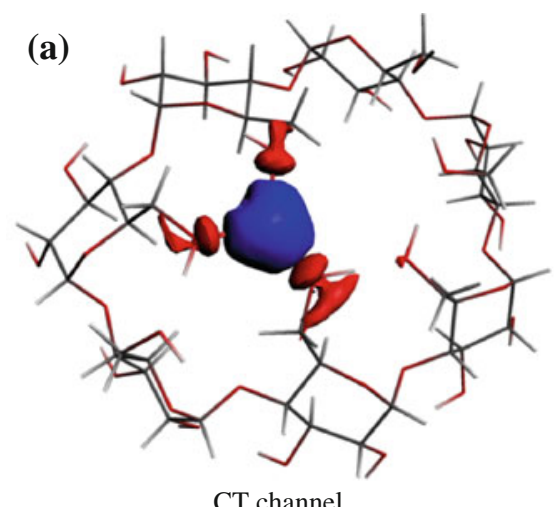

(structure $\mathrm{C}$ of $\mathrm{Zn}^{2+} / \beta-\mathrm{CD}$ )
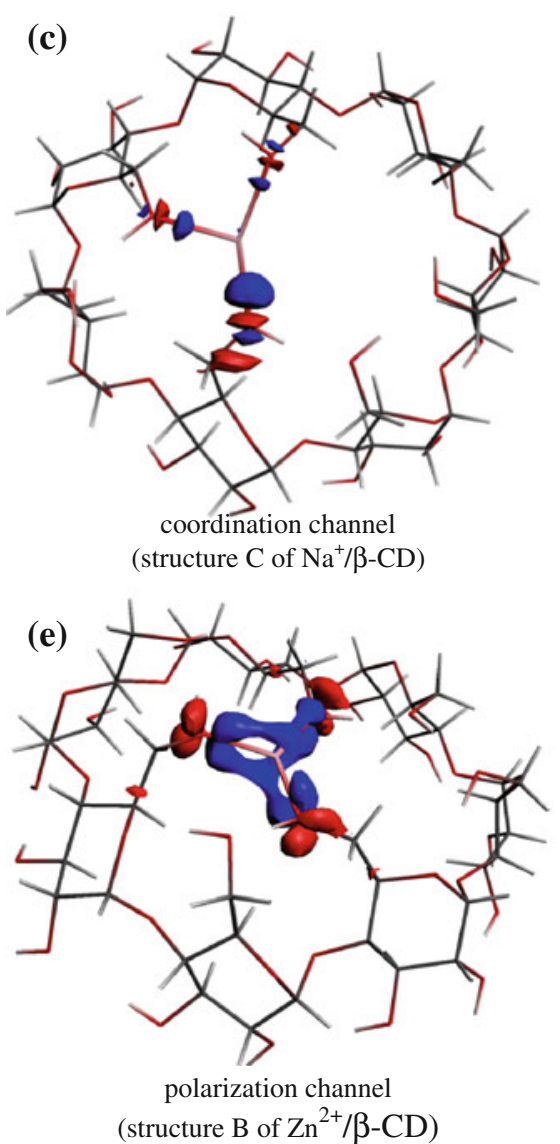

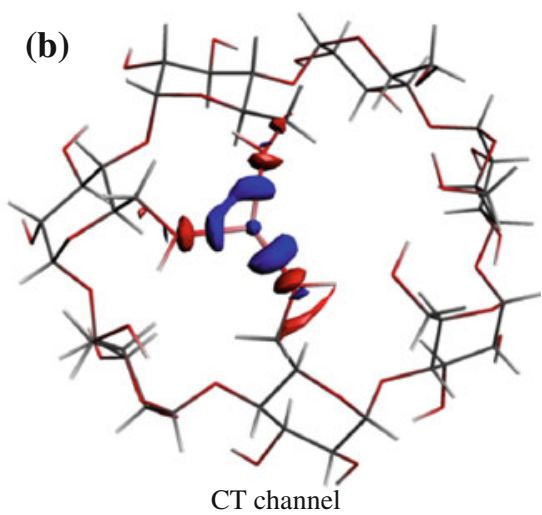

(structure $\mathrm{C}$ of $\mathrm{Mg}^{2+} / \beta-\mathrm{CD}$ )

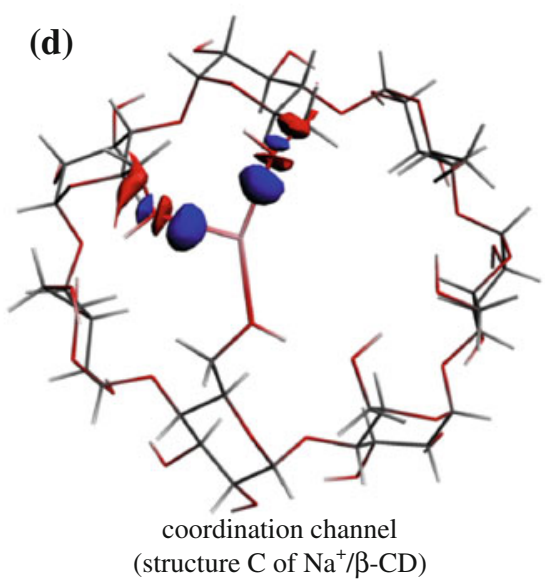

(f)

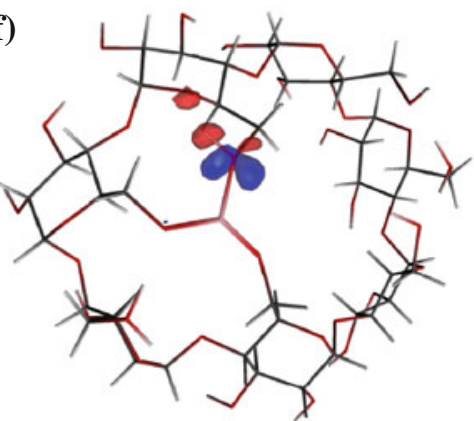

polarization channel (structure $\mathrm{C}$ of $\mathrm{Al}^{3+} / \beta-\mathrm{CD}$ ) on discrete solvent models, but at significantly lower computational cost. One should remember that PCM model is only applicable when such a model can even get the correct experimental species and conformer, which is not always the case [43, 44, 46]. Hence, one must be very careful when one uses the PCM model for strongly interacting solvents like water, which can stabilize structures and species not stable in the absence of the hydrogen bonded water-solute network which stabilizes the complex. Hence, the concept of a hydrated species and/or complex. The best agreement between the explicit-solvation and the
PCM results for two types of solvents has been obtained for Van der Waals surface [45]. This surface type and UFF radii were applied in this work. It is assumed that $\beta$-CD molecule forms the first coordination shell. For complexes with low coordination number $(1 \mathrm{~A}-1 \mathrm{C})$, one explicit water molecule was taken into account since complexes with lower coordination number are more sensitive on the number of solvent molecule beyond the first solvation shell.

In Table 6, we have listed PCM interaction energies. The interaction energies in aqueous solution are smaller 
Table 6 PCM interaction energies in kcal/mole for both groups of conformers (structures 1A-1D see Fig. 3; structures 2A-2E see Fig. 4)

\begin{tabular}{|c|c|c|c|c|c|}
\hline & $\mathrm{Na}^{+} / \beta-\mathrm{CD}$ & $\mathrm{Mg}^{2+} / \beta-\mathrm{CD}$ & $\mathrm{Al}^{3+} / \beta-\mathrm{CD}$ & $\mathrm{Cu}^{+} / \beta-\mathrm{CD}$ & $\mathrm{Zn}^{2+} / \beta-\mathrm{CD}$ \\
\hline $1 \mathrm{~A}$ & -8.2 & -23.3 & & -96.4 & -19.2 \\
\hline 1B & 2.5 & -12.1 & -359.9 & -79.4 & -24.2 \\
\hline $1 \mathrm{C}$ & -5.6 & -24.3 & -368.2 & -93.4 & -37.0 \\
\hline 1D & & 4.7 & -379.5 & & -10.3 \\
\hline $2 \mathrm{~A}$ & 27.8 & 12.0 & -354.5 & -59.8 & 3.5 \\
\hline $2 \mathrm{~B}$ & 20.5 & 8.6 & -365.2 & -74.1 & -1.4 \\
\hline $2 \mathrm{C}$ & 21.8 & 13.2 & -361.5 & -63.8 & 4.3 \\
\hline $2 \mathrm{D}$ & 32.8 & 13.5 & -362.8 & -51.3 & 2.9 \\
\hline \multirow[t]{2}{*}{$2 \mathrm{E}$} & 21.5 & 0.7 & -365.3 & -70.7 & -12.5 \\
\hline & $\mathrm{Na}^{+} / \beta-\mathrm{CD} / \mathrm{H}_{2} \mathrm{O}$ & $\mathrm{Mg}^{2+} / \beta-\mathrm{CD} / \mathrm{H}_{2} \mathrm{O}$ & $\mathrm{Al}^{3+} / \beta-\mathrm{CD} / \mathrm{H}_{2} \mathrm{O}$ & $\mathrm{Cu}^{+} / \beta-\mathrm{CD} / \mathrm{H}_{2} \mathrm{O}$ & $\mathrm{Zn}^{2+} / \beta-\mathrm{CD} / \mathrm{H}_{2} \mathrm{O}$ \\
\hline $1 \mathrm{~A}^{\prime}$ & -15.6 & -14.2 & & -103.7 & -29.2 \\
\hline $1 B^{\prime}$ & -8.4 & -25.4 & -397.8 & -102.1 & -34.5 \\
\hline $1 \mathrm{C}^{\prime}$ & -13.6 & -36.2 & -410.5 & -104.5 & -45.6 \\
\hline
\end{tabular}

The last part of the Table includes interaction energies of systems 1A-1C with additional water molecule coordinated to central atom

than in vacuum. This is not surprising since in the solvent the stabilization of a free ion is larger than the stabilization of the complex and $\beta$-CD molecule. Geometries of all located conformers were re-optimized. 1D-type vacuum conformers for monocations $\left(\mathrm{Cu}^{+} / \beta-\mathrm{CD}\right.$ and $\left.\mathrm{Na}^{+} / \beta-\mathrm{CD}\right)$ disappear. They transformed into $1 \mathrm{~A}$-type conformers. The coordination number for 1D-type conformers of $\mathrm{Zn}^{2+} / \beta$ $\mathrm{CD}$ and $\mathrm{Mg}^{2+} / \beta-\mathrm{CD}$ is equal 4 . These structures resemble $\mathrm{Al}^{3+} / \beta$-CD one (1D conformer in vacuum and in water). Except for $\mathrm{Mg}^{2+} / \beta-\mathrm{CD}$ (conformer 1D) and $\mathrm{Na}^{+} / \beta-\mathrm{CD}$ (conformer 1B), interaction energies of the first group of conformers are negative. In the second group of conformers, negative interaction energies are for $\mathrm{Al}^{3+} / \beta-\mathrm{CD}$ and $\mathrm{Cu}^{+} / \beta$-CD. For $\mathrm{Zn}^{2+} / \beta-\mathrm{CD}$, only conformers $2 \mathrm{~B}$ and $2 \mathrm{E}$ have negative interaction energies. None of the interaction energies is negative for $\mathrm{Na}^{+} / \beta$-CD and $\mathrm{Mg}^{2+} / \beta-\mathrm{CD}$. The interaction energy of the most stable conformer from the first group is more negative than for the most stable conformer from the second group.

The interaction energy for conformer $1 \mathrm{D}$ is preferred by $\mathrm{Al}^{3+} / \beta$-CD. Dications prefer conformers $1 \mathrm{C}$. Monocations prefer coordination mode $1 \mathrm{~A}$. Differences in relative stabilization energies for $\mathrm{Zn}^{2+} / \beta-\mathrm{CD}, \mathrm{Mg}^{2+} / \beta-\mathrm{CD}$, and $\mathrm{Na}^{+} / \beta$-CD complexes are not so pronounced as was observed in vacuum. PCM calculations reduce the spread in relative energies compared to standard vacuum calculations. Water molecule that was introduced to increase coordination number of complexes $1 \mathrm{~A}-1 \mathrm{C}$ affects the interaction energies. All interaction energies $\left(E_{\mathrm{int}}=\right.$ $\left.E_{\mathrm{X} / \beta-\mathrm{CD}}-E_{\mathrm{X}}-E_{\beta-\mathrm{CD}}-E_{\mathrm{H}_{2} \mathrm{O}}\right)$, expect for $\mathrm{Mg}^{2+} / \beta-\mathrm{CD}$, are more negative. In the case of $\mathrm{Cu}^{+} / \beta-\mathrm{CD}$ conformer, $1 \mathrm{C}$ is more stable than $1 \mathrm{~A}$; however, the difference is subtle. Based on data in Table 6 , the following stability sequence is obtained: $\mathrm{Al}^{3+} / \beta-\mathrm{CD}>\mathrm{Cu}^{+} / \beta-\mathrm{CD}>\mathrm{Zn}^{2+} /$ $\beta-\mathrm{CD}>\mathrm{Mg}^{2+} / \beta-\mathrm{CD}>\mathrm{Na}^{+} / \beta-\mathrm{CD}$.

\section{Conclusions}

This theoretical DFT study on the interactions between $\beta$-cyclodextrin and $\mathrm{Na}^{+}, \mathrm{Mg}^{2+}, \mathrm{Al}^{3+}, \mathrm{Cu}^{+}$, and $\mathrm{Zn}^{2+}$ ions evidenced formation of two groups of conformers. The first group structures preserved the initial orientation of glucopyranose residues. In the second group of conformers, the initial orientation of the glucopyranose residues inside $\beta$-CD ligand was modified on binding, showing the so-called induced-fit binding effect. The smaller rim hydroxyl oxygen atoms of the ligand formed bonds with cation in all structures of the first group. One of coordination modes in this group allowed $\mathrm{O} 4$ and $\mathrm{O} 5$ atoms to form bonds. Apart from primary hydroxyl oxygens, secondary $\mathrm{O} 2$ and $\mathrm{O} 3$ hydroxyl oxygen atoms formed bonds with cation. Such coordination pattern required reorientation of glucopyranose residues.

The nature of cation binding by $\beta$-CD ligand was investigated by energy decomposition analysis. The system interaction energy was decomposed into ES, orb and Pauli contributions using Ziegler-Rauk scheme. Further partitioning of orb energy into NOCV contributions allowed one to distinguish $\sigma$-charge-transfer, $\sigma$-coordination and $\sigma, \pi$-polarization channels. The total electrostatic energy, i.e., the sum of ES energy and polarization energy (coordination and polarization channels) is the dominating term in the interaction energy. The $\sigma$-charge-transfer channel dominates orb energy especially for $\mathrm{Cu}^{+}$and $\mathrm{Zn}^{2+}$. Strong contribution of coordination and polarization channels 
indicates that polarizable force-fields should be used in classical molecular dynamic simulations instead of nonpolarizable force-fields.

The stability of $\beta$-CD complexes in vacuum increase with the cation charge. Complexes formed by transition metal ions were more stable than these of the same charge but from the main groups. Both located groups of conformers were close in energy for dications. Monocations and $\mathrm{Al}^{3+}$ preferred the conformers that preserved orientation of glucopyranose residues. The stability sequence changes in an aqueous environment. The complexes formed with $\mathrm{Cu}^{+}$are more stable than complexes formed with dications. The conformers from the first group were more stable than from the second group.

Acknowledgments The calculations were carried out with the equipment purchased thanks to the financial support of the European Regional Development Fund in the framework of the Polish Innovation Economy Operational Program (contract no. POIG.02. 01.00-12-023/08). The authors acknowledge computational grants MNiSW/SGI3700/UJ/161/2006, MNiSW/IBM_BC_HS21/UJ/060/ 2007, MNiSW/SGI4700/UJ/061/2007, and MEiN/SGI3700/UJ/108/ 2006 from Cyfronet.

Open Access This article is distributed under the terms of the Creative Commons Attribution Noncommercial License which permits any noncommercial use, distribution, and reproduction in any medium, provided the original author(s) and source are credited.

\section{References}

1. Szejtli J (1998) Introduction and general overview of cyclodextrin chemistry. Chem Rev 98:1743-1753

2. Loftsson T, Duchene D (2007) Cyclodextrins and their pharmaceutical applications. Int J Pharm 329:1-11

3. Juvancz Z, Kendrovics RB, Ivanyi R, Szente L (2008) The role of cyclodextrins in chiral capillary electrophoresis. Electrophoresis 29:1701-1712

4. Rekharsky MV, Inoue Y (1998) Complexation thermodynamics of cyclodextrins. Chem Rev 98:1875-1917

5. Connors KA (1997) The stability of cyclodextrin complexes in solution. Chem Rev 97:1325-1357

6. Liu L, Guo Q-X (2004) Use of quantum chemical methods to study cyclodextrin chemistry. J Incl Phenom Macrocycl Chem 50:95-103

7. Britto MAFO, Nascimnento CS Jr, Dos Santos HF (2004) Structural analysis of cyclodextrins: a comparative study of classical and quantum mechanical methods. Quim Nova 27:882-888

8. Pinjari RV, Joshi KA, Gejji SP (2007) Theoretical studies on hydrogen bonding, NMR chemical shifts and electron density topography in $\alpha, \beta$ and $\gamma$-cyclodextrin conformers. J Phys Chem A 111:13583-13589

9. Heine T, Dos Santos HF, Patchkovskii S, Duarte HA (2007) Structure and dynamics of beta-cyclodextrin in aqueous solution at the density-functional tight binding level. J Phys Chem A 111:5648-5654
10. Snor W, Liedl E, Weiss-Greiler P, Karpfen A, Viernstein H, Wolschann P (2007) On the structure of anhydrous beta-cyclodextrin. Chem Phys Lett 441:159-162

11. Anconi CPA, Nascimento CS Jr, Fedoce-Lopes J, Dos Santos HF, De Almeida WB (2007) Ab initio calculations on low-energy conformers of alpha-cyclodextrin. J Phys Chem A 111:12127-12135

12. Jimenez V, Alderete JB (2008) Hartree-Fock and density functional theory study of alpha-cyclodextrin conformers. J Phys Chem A 112:678-685

13. Nascimento CS, Dos Santos HF, De Almeida WB (2004) Theoretical study of the formation of the alpha-cyclodextrin hexahydrate. Chem Phys Lett 397:422-428

14. Rizzarelli E, Vecchio G (1999) Metal complexes of functionalized cyclodextrins as enzyme models and chiral receptors. Coord Chem Rev 188:343-364

15. Cai Y, Tarr MA, Xu G, Yalcin T, Cole RB (2003) Dication induced stabilization of gas-phase ternary beta-cyclodextrin inclusion complexes observed by electrospray mass spectrometry. J Am Soc Mass Spectrom 14:449-459

16. Zhang Y, Xu W (1989) The aldol condensation catalyzed by metal(II)- $\beta$-cyclodextrin complexes. Synth Commun 19:12911296

17. Ziegler T, Rauk A (1977) On the calculation of bonding energies by the Hartree Fock Slater method. I. The transition state method. Theor Chim Acta 46:1-10

18. Mitoraj M, Michalak A (2007) Natural orbitals for chemical valence as descriptors of chemical bonding in transition metal complexes. J Mol Model 13:347-355

19. Frisch MJ, Trucks GW, Schlegel HB, Scuseria GE, Robb MA, Cheeseman JR, Scalmani G, Barone V, Mennucci B, Petersson GA, Nakatsuji H, Caricato M, Li X, Hratchian HP, Izmaylov AF, Bloino J, Zheng G, Sonnenberg JL, Hada M, Ehara M, Toyota K, Fukuda R, Hasegawa J, Ishida M, Nakajima T, Honda Y, Kitao O, Nakai H, Vreven T, Montgomery JJ Jr, Peralta JE, Ogliaro F, Bearpark M, Heyd JJ, Brothers E, Kudin KN, Staroverov VN, Kobayashi R, Normand J, Raghavachari K, Rendell A, Burant JC, Iyengar SS, Tomasi J, Cossi M, Rega N, Millam JM, Klene M, Knox JE, Cross JB, Bakken V, Adamo C, Jaramillo J, Gomperts R, Stratmann RE, Yazyev O, Austin AJ, Cammi R, Pomelli C, Ochterski JW, Martin RL, Morokuma K, Zakrzewski VG, Voth GA, Salvador P, Dannenberg JJ, Dapprich S, Daniels AD, Farkas O, Foresman JB, Ortiz JV, Cioslowski J, Fox DJ (2009) Gaussian 09, revision A.02; Gaussian, Inc, Wallingford. http://www.gaussian.com

20. Stephens PJ, Devlin FJ, Chabalowski CF, Frisch MJ (1994) Ab initio calculation of vibrational absorption and circular dichroism spectra using density functional force fields. J Phys Chem A 98:11623-11627

21. Styrcz A, Mrozek J, Mazur G (2011, in press) A neural-network controlled dynamic evolutionary scheme for global molecular geometry optimization. Int J Appl Math Comput Sci 21(3) (in press)

22. Schmidt MW, Baldridge KK, Boatz JA, Elbert ST, Gordon MS, Jensen JH, Koseki S, Matsunaga N, Nguyen KA, Su S, Windus TL, Dupuis M, Montgomery JA (1993) General atomic and molecular electronic structure system. J Comput Chem 14:1347-1363

23. GAMESS v, Jan. 2003 (R2), Iowa State University. http://www. msg.ameslab.gov/gamess/

24. Mayer I (1985) Bond orders and valences in the SCF theory: a comment. Theor Chim Acta 67:315-322

25. Mayer I (1986) Bond orders and valences from ab initio wave functions. Int J Quantum Chem 29:477-483

26. Mrozek J, Nalewajski RF, Michalak A (1998) Exploring bonding patterns of molecular systems using quantum mechanical bond multiplicities. Pol J Chem 72:1779-1791 
27. Nalewajski RF, Mrozek J, Michalak A (1997) Two-electron valence indices from the Kohn-Sham orbitals. Int J Quantum Chem 61:589-601

28. Mitoraj MP, Michalak A, Ziegler T (2009) A combined charge and energy decomposition scheme for bond analysis. J Chem Theory Comput 5:962-975

29. Te VG, Bickelhaupt FM, Baerends EJ, Fonseca GC, Van GSJA, Snijders JG, Ziegler T (2001) Chemistry with ADF. J Comput Chem 22:931-967

30. Van Lenthe E, Baerends EJ (2003) Optimized Slater-type basis sets for the elements 1-118. J Comput Chem 24:1142-1156

31. Humphrey W, Dalke A, Schulten K (1996) VMD-visual molecular dynamics. J Mol Graph 14:33-38

32. Zabel V, Saenger W, Mason SA (1986) Topography of cyclodextrin inclusion complexes. Part 23. Neutron diffraction study of the hydrogen bonding in beta-cyclodextrin undecahydrate at $120 \mathrm{~K}$ : from dynamic flip-flops to static homodromic chains. J Am Chem Soc 108:3664-3673

33. Lindner K, Saenger W (1982) Topography of cyclodextrin complexes. Part XVII. Crystal and molecular structure of cycloheptaamylose dodecahydrate. Carbohydr Res 99:103-115

34. Norkus E (2009) Metal ion complexes with native cyclodextrins. An overview. J Incl Phenom Macrocycl Chem 65:237-248

35. Stephens PJ, Jalkanen KJ, Kawiecki RW (1990) Theory of vibration rotational strengths - comparison of a priori theory and approximate models. J Am Chem Soc 112:6518-6529

36. Szewczyk B, Sokalski WA, Leszczynski J (2002) Optimal methods for calculation of the amount of intermolecular electron transfer. J Chem Phys 117:6952-6958

37. Khaliullin RZ, Cobar EA, Lochan RC, Bell AT, Head-Gordon M (2007) Unravelling the origin of intermolecular interactions using absolutely localized molecular orbitals. J Phys Chem A 111:8753-8765
38. Korchowiec J, Uchimaru $\mathrm{T}$ (2000) New energy partitioning scheme based on the self-consistent charge and configuration method for subsystems: application to water dimer system. J Chem Phys 112:1623-1633

39. Reed AE, Curtiss LA, Weinhold F (1988) Intermolecular interactions from a natural bond orbital, donor-acceptor viewpoint. Chem Rev 88:899-926

40. Kitaura K, Morokuma K (1976) A new energy decomposition scheme for molecular interactions within the Hartree-Fock approximation. Int J Quantum Chem 10:325-340

41. Stevens WJ, Fink WH (1987) Frozen fragment reduced variational space analysis of hydrogen bonding interactions. Application to the water dimer. Chem Phys Lett 139:15-22

42. Korchowiec J, Korchowiec B, Priebe W, Rogalska E (2008) DFT study on the selectivity of complexation of metal cations with a dioxadithia crown ether ligand. J Phys Chem A 112:13633-13640

43. Jalkanen KJ, Degtyarenko IM, Nieminen RM, Cao X, Nafie LA, Zhu F, Barron LD (2008) Role of hydration in determining the structure and vibrational spectra of L-alanine and $\mathrm{N}$-acetyl Lalanine $N$-methylamide in aqueous solution: a combined theoretical and experimental approach. Theor Chem Acc 119:191210

44. Jürgensen VW, Jalkanen KJ (2006) The VA, VCD, Raman and ROA spectra of tri-L-serine in aqueous solution. Phys Biol 3:S63S79

45. Eilmes A, Kubisiak P (2010) Relative complexation energies for $\mathrm{Li}+$ ion in solution: molecular level solvation versus polarizable continuum model study. J Phys Chem A 114:973-979

46. Jalkanen KJ, Nieminen RM, Frimand K, Bohr J, Bohr H, Wade RC, Tajkhorshid E, Suhai S (2001) A comparison of aqueous solvent models used in the calculation of the Raman and ROA spectra of L-alanine. Chem Phys 265:125-151 